\title{
Giant villous duodenal adenoma with malignant change: an unusual cause of obstructive jaundice
}

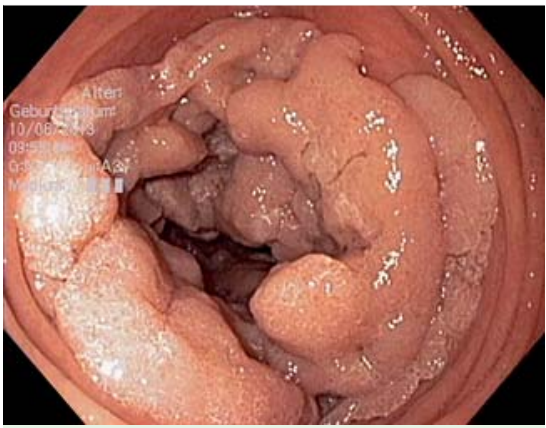

Fig. 1 Endoscopic view showing a circumferential villous adenoma carpeting almost the entire duodenal wall.

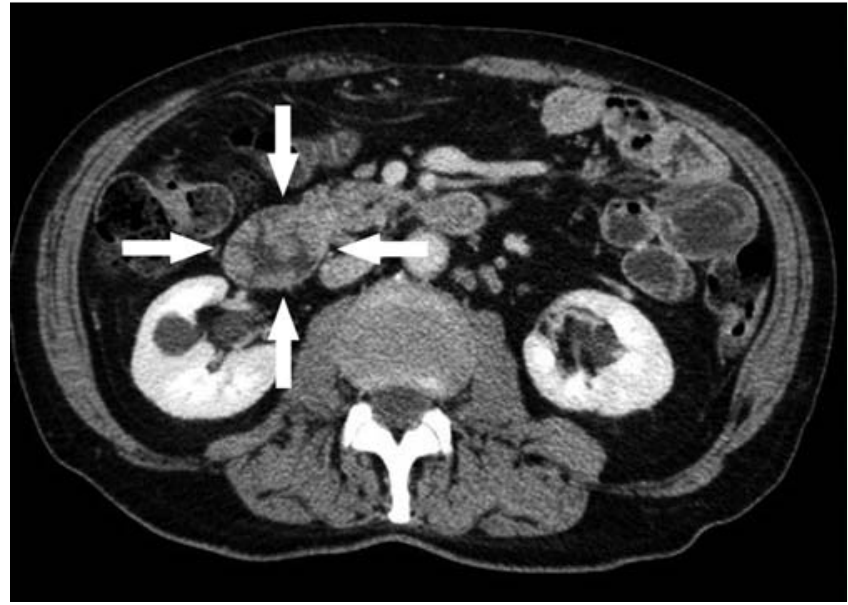

Fig. 2 Abdominal computed tomography (CT) scan showing an irregular polypoid tumor mass protruding into the duodenal lumen (arrows).

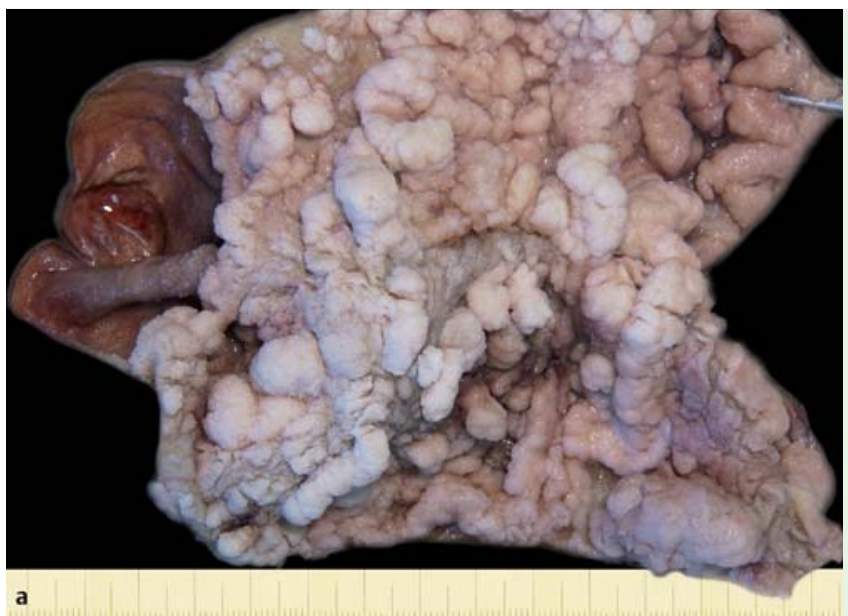

Fig. 3 Macroscopic appearance of the resection specimen showing: a a huge intraduodenal villous adenoma, measuring $12.5 \mathrm{~cm}$ in its largest diameter; $\mathbf{b}$ the cut surface of the ampulla, which was yellowwhite, firm, and suspicious of malignancy (arrows).

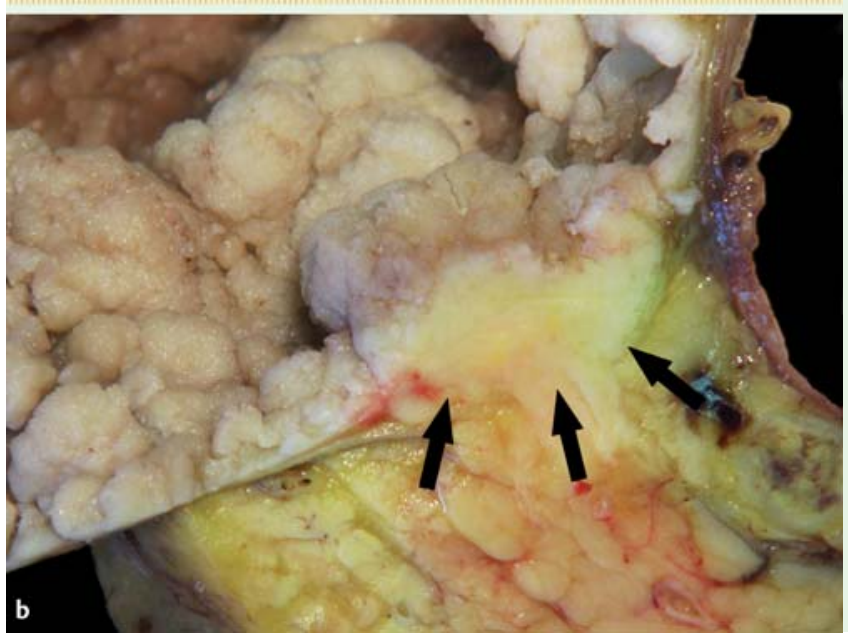

A 67-year-old man presented with nonspecific right upper quadrant pain and icterus. Laboratory analysis revealed marked cholestasis: alkaline phosphatase 607U/L (normal 35-129U/L), gamma glutamyltransferase 1595U/L (normal 0$66 \mathrm{U} / \mathrm{L}$ ), and total bilirubin $27.2 \mathrm{mg} / \mathrm{dL}$ (normal 0-1 mg/dL). At endoscopy, a huge villous duodenal adenoma was detected, which covered almost the entire duodenal wall ( Fig. 1). Intubation of the ampulla of Vater was impossible. A computed tomography (CT) scan showed an irregular, polypoid tumor that was protruding into the duodenal lumen, but was confined to the bowel wall ( $\bullet$ Fig. 2 ).

The pancreaticoduodenectomy specimen subsequently showed an intraduodenal villous tumor measuring $12.5 \mathrm{~cm}$ in its largest diameter. The cut surface of the ampulla was firm, yellow-white, and suspicious of malignancy ( Fig. 3). This area measured $1.5 \mathrm{~cm}$ in its largest diameter. Histology revealed a villous adenoma (with low and high grade dysplasia) with progression to poorly differentiated ampullary adenocarcinoma that was invading both the pancreas and the peripancreatic soft tissue ( Fig.4). Seven regional lymph node metastases were identified. The patient's postoperative course was uneventful and he was discharged in good condition 10 days after surgery.

Villous adenomas of the duodenum have a predilection for the ampullary region, tend to present with obstructive jaundice, especially if malignancy is present, and 


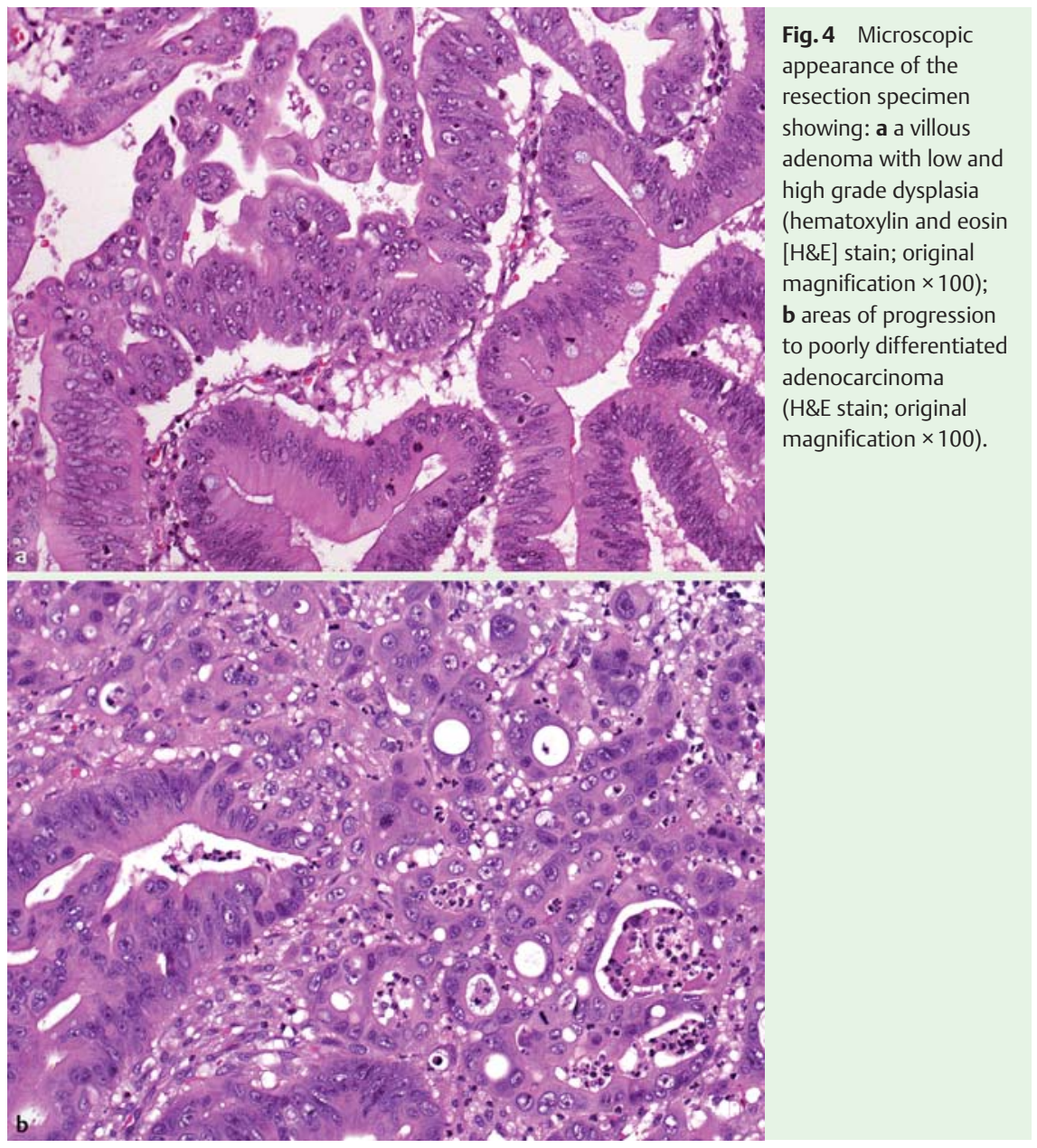

frequently show cancerous change [2]. It has been reported by Pezet et al. [3] that jaundice, but not tumor size, is predictive of malignancy. Even when biopsies are available, the diagnosis of cancer is frequently missed and it may be impossible to assess the presence of invasive adenocarcinoma without complete excision of the lesion [2].
Endoscopy_UCTN_Code_CCL_1AZ_2AI

Competing interests: None

\section{Lisa Setaffy ${ }^{1}$, Franz Siebert ${ }^{2}$, Jörg Tschmelitsch ${ }^{3}$, Heinz Lackner ${ }^{4}$, Cord Langner ${ }^{1}$}

${ }^{1}$ Institute of Pathology, Medical University, Graz, Austria

${ }^{2}$ Department of Internal Medicine, Krankenhaus der Barmherzigen Brüder, Academic Teaching Hospital,

St. Veit/Glan, Austria

${ }^{3}$ Department of Surgery, Krankenhaus der Barmherzigen Brüder, Academic Teaching Hospital, St. Veit/Glan, Austria

${ }^{4}$ Department of Radiology, Krankenhaus der Barmherzigen Brüder, Academic Teaching Hospital, St. Veit/Glan, Austria

\section{References}

1 Sharma C, Eltawil KM, Renfrew PD et al. Advances in diagnosis, treatment and palliation of pancreatic carcinoma: 1990-2010. World J Gastroenterol 2011; 17: 867-897

2 Ryan DP, Schapiro RH, Warshaw AL. Villous tumors of the duodenum. Ann Surg 1986; 203: 301-306

3 Pezet D, Rotman N, Slim K et al. Villous tumors of the duodenum: a retrospective study of 47 cases by the French Associations for Surgical Research. J Am Coll Surg 1995; 180: $541-544$

Bibliography

DOI http://dx.doi.org/

10.1055/s-0033-1344795

Endoscopy 2013; 45: E376-E377

(C) Georg Thieme Verlag KG

Stuttgart · New York

ISSN 0013-726X

Corresponding author

Cord Langner, MD

Institute of Pathology

Medical University Graz

Auenbruggerplatz 25

A-8036 Graz

Austria

Fax: $+43-316-38513432$

cord.langner@medunigraz.at 